\title{
Identidade, aposentadoria e terceira idade ${ }^{1}$
}

\author{
Sergio Antonio Carlos ${ }^{2}$ \\ Maria da Graça Correa Jacques ${ }^{2}$ \\ Sandra Vieira Larratéa ${ }^{2}$ \\ Olga Collin et Heredia ${ }^{3}$
}

\section{Resumo}

A associação corrente entre velhice e aposentadoria remete a uma representação coletiva em que o velho é percebido não mais como um agente de bens e serviços e, conseqüentemente, marginalizado nos contextos sociais contemporâneos pautados pelo valor produtivo. A partir da análise e interpretação de depoimentos de pessoas com mais de 60anos e aposentadas há pelo menos 5anos, propõe-se uma compreensão para a permanência real ou simbólica do vínculo com o mundo formal do trabalho. O material empírico recolhido permite constatar que são os valores e idéias de referência da cultura de classe trabalhadora que continuam dando sentido e referência para estas pessoas; ainda, verifica-se a ocorrência de uma "dupla aposentadoria" no plano subjetivo: a primeira, legal, por tempo de serviço, e a segunda, nem sempre com reconhecimento oficial, mas determinada pelos limites impostos pelo corpo (doenças e/ou idade) e pelo processo de exclusão do mundo do trabalho.

Palavras-Chave: identidade; terceira idade; aposentadoria.

\section{Abstract}

The current association betw een old age and retirement sends us into a collective representation where seniors are not perceived as producers for goods and services, thus marginalized in the contemporary social contexts noted for the valuing of productiveness. From the analyzes and interpretation of the declarations of the individuals over 60 and retired for at least 5years, it was proposed an understanding for the real or symbolic permanence of the link with the formal work world. The empirical material collected allowed for the realization that it is the values and the cultural reference ideas of the work class that keep giving meaning and reference to these individuals; furthermore, it was noted the occurrence of a "double retirement" in the subjective plan: the first, legal and for the years of work, and the second, not alw ays officially recognized, but determined by the limits imposed by the body (illness and/or age), and by the process of exclusion from the work world.

Key words: identity; third age; retirement.

\footnotetext{
${ }^{1} \mathrm{O}$ texto se fundamenta nos dados empíricos coletados por um trabalho de investigação, que contou com o financiamento da FAPERGS e do CNPq.

${ }^{2}$ Instituto de Psicologia da UFRGS.

${ }^{3}$ CEDOPE-UNISINOS
} 


\section{Introdução}

"A memória do trabalho é o sentido, é a justificativa de toda uma biografia. Quando o Sr. Amadeo fecha a história de sua vida, qual o conselho que dá? De tolerância para os velhos, tolerância mesmo com aqueles que se transviaram na juventude. Eles também trabalharam." (Bosi, 1987, p. 399)

O parágrafo final da obra de Ecléa Bosi, "Lembranças de Velho", assinala a importância e a positividade conferida à capacidade de trabalho e de ser trabalhador no contexto social contemporâneo. Remete a uma reflexão sobre o papel do velho neste contexto enquanto não mais produtor de bens e serviços, o que introduz a questão da aposentadoria, enquanto possibilidade de ausência de trabalho e de suas implicações nas trajetórias e nos cotidianos de vida.

O prolongamento da expectativa de vida e o conseqüente crescimento numérico da população de idosos neste final de século coincide com a inadimplência de alguns sistemas de previdência. Ancorad os em interpretações econômicas neo-liberais, alguns países propõem reformas estruturais nos sistemas de aposentadoria que impõem novas regras que obstaculizam o processo. Qualificações depreciativas são evocadas com referência aos aposentados, depositários das causas explicativas para o colapso dos sistemas previdenciários sem uma análise mais apurada dos modelos propostos e das formas de gestão dos recursos arrecadados.

Neste contexto, o tema aposentadoria ganha significância e, em geral, as análises propostas não privilegiam o aspecto subjetivo que lhe é inerente. Além disso, a questão do idoso vem ganhando representatividade, visto o crescimento deste segmento populacional no mundo. O limite cronológico proposto pela ONU, em 1982 para o início da chamada terceira idade toma por base a idade da aposentadoria estabelecida na maioria dos países. Tal limite proposto induz a associação corrente entre velhice e aposentadoria, que embora na prática nem sempre se confun- 
dam, enquanto associadas, remetem a uma representação coletiva em que o velho é percebido como não mais produtor de bens e serviços e, portanto, marginalizado nos contextos sociais pautados pelo valor produtivo.

Todas essas considerações fundamentam uma proposta de análise sobre a interrelação entre o trabalho, a aposentadoria e a terceira idade, interrelação esta que ganha destaque quando reformas constitucionais, no Brasil, impõem novas regras para a aposentadoria que, de forma geral, implicam em um prolongamento do tempo de trabalho. Neste recorte, privilegia-se o ponto de vista subjetivo expresso nos depoimentos de treze pessoas com 60anos e mais, aposentados há pelo menos cinco anos. São depoimentos que se constituem em histórias de vida autobiográficas coletadas e organizadas em uma espécie de "banco de dados" que oportunizam, parafraseando Ecléa Bosi (1987, p. 1), “... registrar a voz e, através dela, a vida e o pensamento dos seres que trabalharam por seus contemporâneos". O material empírico fornece informações sobre as vivências experimentadas subjetivamente e sobre as estratégias de enfrentamento frente às alterações decorrentes do passar dos anos. Orecorte analítico proposto privilegia uma abordagem qualitativa de exame, priorizando as determinações do contexto sócio-cultural como modos explicativos de compreensão das experiências subjetivas relatadas em relação ao trabalho, à aposentadoria e à terceira idade.

\section{A aposentadoria e o vínculo com o trabalho}

É certo que a história do trabalho começou quando o homem buscou os meios para a satisfação de suas necessidades e que esta busca se reproduziu historicamente através de toda a sua ação humana para sobrevivência. É certo, também, que estas necessidades se ampliaram e se propagaram entre os homens, criando organizações técnicas e relações sociais que acabaram por determinar a condição histórica do trabalho. Condição histórica que vai se expressar nos diferentes significados, nem sempre congruentes entre si, que o vocábulo trabalho evoca, a ponto de 
Agnés Heller (1989) propor não o emprego de uma única definição conceitual, mas operar com diversas aproximações e conceitos distintos. Conforme a autora:

“... com isto, não quero demonstrar que estas aproximações sejam insuficientes, demasiado limitadas ou falsas. Pelo contrário, quero mostrar que todas, sem exceção, afirmam algo de verdadeiro do trabalho." (p.78)

A ausência de um conceito fechado e definitivo sobre trabalho permite que diferentes atividades sejam classificadas como tal e são as experiências subjetivas ancoradas nas representações coletivas do contexto sócio-cultural que determinam estas qualificações. Portanto, ao evocar o predicativo trabalho para qualificar uma diversidade de atividades realizadas como oposição ao ócio (atividades não necessárias à vida do indivíduo e ao processo vital da sociedade), o vínculo com o trabalho se mantém, mesmo com a aposentadoria, conferindo um sentido de utilidade e inserção social.

Para compreender todo este processo de significação subjetiva, se faz necessário atentar à transformação positiva do significado verbal da própria palavra trabalho, que até a época Moderna ficou sempre muito associada a sofrimento, penalização, esforço.

A transformação moderna do significado da palavra trabalho, em sua nova positividade, expressa a sua ascensão como a mais valorizada das atividades humanas, que encontra seu suporte definitivo na consolidação do modelo capitalista de produção e que vai se manifestar na produção teórica dos séculos XVIII e XIX Conforme lembra Hanna Arendt (1981, p. 113), o trabalho ascendeu:

“... da mais humilde e desprezível posição à mais alta categoria, como a mais estimada de todas as atividades humanas, (que) começou quando Locke descobriu que é a fonte de toda a propriedade; prosseguiu quando Adam Smith afirmou que era fonte de toda a riqueza, e atingiu seu climax em Marx quando o trabalho passou a ser a origem de toda a produtividade e a expressão da própria humanidade do hom em." 
Segundo Edgar de Decca (1988), a dimensão da glorificação do trabalho encontrou suporte definitivo no surgimento da fábrica, na qual o trabalho pode se apresentar em toda a sua positividade e que se impôs como instrumento para incrementar a produtividade e, principalmente, como instrumento para controlar, disciplinar e hierarquizar o processo de trabalho. Conseqüentemente, a introjeção do "sistema de fábrica", movida pela crença do poder positivo do trabalho organizado, não se rompe com o ato formal da aposentadoria, sendo freqüente a permanência no trabalho quer através de uma troca de empresa com atividade semelhante ou não (em geral do setor público para o setor privado), quer, ainda, uma continuidade na mesma empresa. Embora o reconhecimento, até certa forma generalizado, do baixo valor pecuniário das aposentadorias, fatores de ordem subjetiva são as principais justificativas para a manutenção do vínculo, como o desejo de reconhecimento e de continuar sentindo-se útil em um conjunto social pautado pelo valor produtivo. Conjunto este estruturado em torno da categoria trabalho e que não oferece outros parâmetros de identificação que permitam significar o cotidiano de vida e lhe conferir valor a não ser através do exercício laboral.

A pregação moral do trabalho edificante, enquanto princípio normativo social, dotado de universalidade, confere registros dicotômicos na representação coletiva sobre o trabalho e o não trabalho (associado ao ócio). Dentro desta lógica imposta pela representação coletiva, não há espaço para pensar na aposentadoria como, contraditoriamente, integrante do mundo do trabalho, como uma oposição contida no ato de trabalhar. Neste sentido, não há uma preparação subjetiva e o ato formal de aposentadoria não significa, necessariamente, um rompimento com o mundo formal do trabalho.

A qualificação trabalho atribuída às diversas atividades realizadas ou a continuidade no mundo formal do trabalho se constituem em modos de evitar a marginalização social e a partir da apropriação da positividade conferida ao ato de trabalhar. Representam a inserção em um conjunto de atributos morais que 
conferem valor e significado à vida em sociedade. Como assinala Alfredo Jerusalinsky (1998, p. 2):

“... como nunca antes na História, hoje o sujeito fica numa total dependência para estabelecer seu valor simbólico de sua equivalência ao objeto seja por possuí-lo, seja por fabricá-lo, seja por dominá-lo ou por usufruílo, eis então que o sujeito encontra seu valor."

\section{A aposentadoria e a ruptura com o trabalho}

Na língua portuguesa, aposentar-se prende-se etimologicamente a hospedagem, abrigo nos aposentos. Considerando que aposento é o mesmo que quarto, alcova, o sentido do termo remete à noção de abrigar-se nos aposentos, no interior da habitação. Em inglês e francês (retired e retraité) também remetem à noção de retirar-se, afastar-se da vida ativa, sendo que no século XVI, retraité significava, também, o lugar onde as pessoas se retiravam para escapar "dos perigos e das modernidades" (Bernd, 1996 p. 21). Todos estes significados se consolidam com a separação entre o espaço doméstico e o espaço do trabalho a partir da implantação do sistema de fábrica. Embora as transformações dos últimos anos representados, principalmente, pelo reconhecimento progressivo das atividades domésticas como trabalho e pela difusão dos homeworks (atividades de bens e serviços produzidos no espaço doméstico) perdura, ainda, como representação coletiva, a associação entre espaço privado e ausência de trabalho e conseqüente desvalor que lhe é atribuído.

No entanto são também sinônimos de aposentar-se reformar-se ou jubilar-se, sendo o primeiro usado na carreira militar e o segundo muito mais no sentido de encher-se de júbilo, alegria ou referente ao desligamento de um aluno por permanência excessiva na escola. Embora algumas línguas latinas como o italiano e espanhol empreguem o termo jubilamento, de conotação positiva, em português este significado não tem uso corrente. 
Com esta análise semântica constata-se a negação do júbilo conferida à ausência de trabalho, embora a associação com a noção de mudança expressa pela palavra reforma e pela noção de recolhimento a que o vocábulo aposento (aposentadoria) remete. A questão que se coloca é por que deixa de ser um ato de júbilo para se tomar depreciativo.

É tanto no desvirtuamento dos sistemas previdenciários que induzem a confusão entre aposentadoria e qualquer outro benefício conferido que se encontra a resposta para essa constatação, mas é, principalmente, no sistema de valores sociais, em que o trabalho representa o principal atributo de valor, que sua ausência deixa de representar uma situação de júbilo para se constituir em um fator de marginalização social.

No entanto, essa mesma representação coletiva admite como justificativas socialmente aceitas para a ausência de trabalho tanto a doença como a idade avançada. E é dentro desta lógica que vai se constatar uma diferença na experiência da aposentadoria quando ela ocorre por tempo de serviço, por doença e por idade. No primeiro caso, não há uma legitimação social quando não acompanhada de um ou dos dois outros fatores e o desligamento definitivo com o trabalho se toma menos freqüente.

Mas mesmo como um ato burocrático e formal, quando há permanência do vínculo configura-se como um espaço de preparação subjetiva para o afastamento futuro. Aposenta-se com um valor simbólico pois coloca para o trabalhador a possibilidade real de um mundo de não trabalho. Esta preparação consiste em uma reorganização da vida familiar, novas relações afetivas, novos espaços de convívio e de relacionamento fora do mundo do trabalho, novas rotinas e até a diminuição gradativa da jornada laboral. Surgem os " trabalhos alternativos", os "hobbies", as experiências em artes e ofícios que implicam em autonomia com relação à organização do trabalho.

Retomando o processo histórico e o disciplinamento proposto pelas formas organizativas que o trabalho adquiriu na sociedade moderna, E. P. Thompson (1991) explora essa nova ordem que se impõe e que se expressa na noção de tempo útil en- 
quanto discurso moralizante constitutivo do imaginário social. Ou ainda, é o que Edgar Decca (1988, p. 18) vai designar como “...mercado, enquanto entidade universal através da qual os homens se reconhecem a si próprios e se opõe a qualquer dispositivo imaginário que coloque a ordem social fora deste universo".

Esse processo de rompimento com a lógica do trabalho formal coincide com o aumento do fator idade e, com muita freqüência, com o aparecimento de doenças. Embora nestes casos se apresente uma justificativa social para a ausência de trabalho, por outro lado, perdas de ordem física, psicológica e social concomitantes tornam a decisão difícil ou ambivalente. Alguns autores como Atchley (citado por Miguel Krassoievitch, 1993), referem-se a algumas fases por que passam aqueles que se afastam do mundo do trabalho. Aponta para uma "fase de desencanto" que segue a "fase de lua de mel" em que, passada a euforia, apresenta-se a d esilusão e, não poucas vezes, um estado depressivo só superado por uma "fase de reorientação" em que o sujeito desenvolve outras opções de atividade, na maioria do tipo social e, em geral, categorizadas como trabalho a partir da amplitude que o conceito de trabalho contempla.

Todo o processo de significação que o ato de aposentadoria enseja prepara para uma segunda aposentadoria, nem sempre formal, mas, principalmente, experenciada como tal. Segunda aposentadoria que quando acompanhada/determinada ou pela doença ou pela velhice recebe aceitabilidade social. No entanto, quando o trabalho se faz presente, mesmo sobre tais circunstâncias, o atributo de valor que lhe é associado ganha em representatividade e garante inserção social.

Por outro lado, as rápidas transformações dos modos de organização sócio-econômica das sociedades contemporâneas e as inovações tecnológicas introduzidas se refletem no modo de trabalhar dessas sociedades. Profissões novas são continuamente criadas bem como novas modalidades de exercício profissional, além do desaparecimento progressivo de determinadas profissões ou, ainda, de determinados modelos de atuação. Esta contínua transformação expulsa do mercado formal um significativo con- 
tingente populacional; a população idosa é, preferentemente, objeto dessa exclusão pela menor flexibilidade em se adaptar e incorporar os novos procedimentos impostos e a inovação tecnológica. Portanto, o afastamento do mundo do trabalho se faz, também, por imperiosas determinações derivadas de uma realidade exterior que se impõe.

Todas essas considerações apontam para uma inevitável ruptura com o mundo do trabalho a medida que aumenta a idade cronológica, quando, então, a aposentadoria ganha, concretamente, o significado de ausência de trabalho, mesmo quando há uma substituição através da realização de atividades variadas com um significado de utilidade social. A questão que se coloca é qual o reflexo deste afastamento sobre a identidade de trabalhador.

\section{O vínculo simbólico com o trabalho}

Entendendo a identidade como um processo de construção histórico e social, aquilo que o indivíduo reconhece como sendo "ele mesmo", significa-se e re-significa-se na trajetória de vida a partir da inserção do indivíduo em conjuntos de relações sociais. É o que Lucien Sève (1989, p. 123) denomina de "formas históricas de individualidade", ou seja, as capacidades características da humanidade, historicamente desenvolvidas, que se encontram objetivadas em um sistema temporal de atividades, fundados sobre o e no conjunto de relações sociais que cada indivíduo e cada geração encontram como dados existentes mediados pelo outro, mas transformados sob o ponto de vista da individualidade psicobiográfica. O mundo concreto do trabalho constitui-se em um "locus" por excelência para essa mediação, por mais não seja, pelo número de horas diárias que os indivíduos a ele se dedicam.

A articulação entre identidade e trabalho vem de uma tradição que confere ao papel social expressividade na constituição da identidade. Dentro dessa tradição, é representativa a proposição de Jirgen Habermas (1990) que propõe que a uma "identidade natural" se segue uma "identidade de papel" que se constitui pela incorporação das unidades simbólicas mediadas pela socialização e, so- 
bre essa, a "identidade do eu" a partir da integração dos papéis sociais através da igualdade e da diferença em relação aos outros.

A importância e a exaltação máximas conferidas ao trabalho na sociedade contemporânea concedem ao papel de trabalhador lugar de destaque entre os papéis sociais representativos do eu. Hanna Arendt (1981), referindo-se à importância do homo faber no mundo contemporâneo, assinala que, ao tentar dizer "quem é", a própria linguagem induz a dizer "o que é", reservando um lugar de destaque ao papel de trabalhador. A esse papel social agregam-se outras qualificações exigidas pelo exercício laboral que se substantivam e se presentificam, constituindo-se em atributos definitórios do eu (ativo, forte, bravo, honesto, etc.)

$\mathrm{Na}$ mesma lógica, Jurandir Freire Costa (1989) registra, na sua prática psiquiátrica em ambulatórios de saúde, a presença de transtornos psíquicos denominados "doença dos nervos" ou "crise nervosa", intimamente associadas com a trajetória e com os percalços da vida laboral e com ameaças à identidade de trabalhador. O autor assinala que essa identidade, associada a outros atributos socialmente valorizados e julgados como constitutivos do ser humano pelo imaginário social, mostra-se à consciência do sujeito como um elemento definitório de grande significação na "identidade psicológica". Esse termo é empregado para diferenciar de outros sistemas identificatórios (identidade social, étnica, religiosa, etc.) por se apresentar não apenas como um atributo do eu ou de algum eu, mas como predicativo universal e genérico definidor do humano.

Da importância da identidade de trabalhador e sua representatividade enquanto identidade do eu, emergem as questões da aposentadoria e suas repercussões. Identidade que se refere, também, à consciência de pertencer a determinado grupo social, inclusive laboral, e à carga afetiva que esta pertença implica. O espaço de trabalho e as categorias profissionais, em geral associados a prestígio ou desprestígio social, proporcionam atributos de qualificação ou desqualificação do eu. Nos casos em que a qualificação é de tal forma representativa, o prefixo ex é evocado para dar conta da identidade quando da aposentadoria. 
Maria de Fátima Santos (1990) aponta que a aposentadoria pode significar uma possível perda do papel profissional. No entanto, mantém-se um vínculo simbólico com o trabalho através da identidade de trabalhador, pois não se rompem os modelos de identificação construídos no passado e apropriados como representativos do eu. Esse modelo identitário se representa como atributo de valor e de inserção social, ancorado nas memórias de um passado de inserção em um grupo profissional e de uma carga afetiva correspondente.

Além disso, entre a população idosa, com freqüência re-significa-se o conceito de trabalho que constitui a identidade de trabalhador a partir dos limites sociais impostos: trata-se de ser ativo em contraposição ao não ativo. Nesta perspectiva, são buscadas atividades remuneradas ou não, preferentemente no espaço público, como forma de garantir reconhecimento social. É o que oportuniza a experiência de sentir-se vivo, já que sua ausência é associada à morte, à exclusão e à segregação em uma sociedade pautada pelo valor produtivo.

\section{Conclusões}

Quando um conjunto social se pauta por valores utilitários, como no caso da sociedade contemporânea, a ausência de inserção no modelo proposto e em suas formas organizativas e relacionais, repercutem na qualidade de vida e na integração social de sua população. É sobre esse enfoque que a articulação entre trabalho, aposentadoria e terceira idade revelam uma dimensão subjetiva e uma repercussão social para além dos dados estatísticos e dos parâmetros econômicos de interpretação.

Qualquer argumentação sobre esta articulação não pode se propor a teorias generalizantes. Ao se inscrever no espaço do humano, convive com a singularidade que o caracteriza. É importante, no entanto, compreender esse humano circunscrito em um contexto sócio-histórico determinante. No caso, um contexto que exalta o ato de trabalhar e lhe confere valor positivo, facultalhe significância ímpar na existência, constituindo-se representante do eu a identidade de trabalhador que lhe é derivada. 
Assim, a aposentadoria pode representar ou não um rompimento com o mundo do trabalho. O rompimento é inevitável quando o fator doença se apresenta associado, fator este reconhecido como uma justificativa aceitável pelo imaginário social. Imaginário social que, também, reconhece e justifica a idade como um obstáculo ao exercício laboral. Neste sentido, as aposentadorias por idade ou por tempo de serviço vão representar experiências diferenciadas que repercutem de maneira também diferenciada, sobre a identidade do eu. Expressam-se no que se poderia chamar de uma "dupla aposentadoria" . A primeira, determinada pelo tempo de serviço, embora legal e que não implica, necessariamente, no afastamento do mundo do trabalho. Pressões econômicas, sociais e culturais concorrem para a permanência no mercado de trabalho, implicando ou não em alterações como o local de trabalho, o tipo de atividade exercida, o regime de trabalho, etc. A segunda, determinada pelos limites impostos pelo corpo (doenças e/ou idade) e pelo processo de exclusão do mercado de trabalho e que, representa, então, concretamente, embora nem sempre formal, o afastamento do mundo do trabalho.

No entanto, o vínculo simbólico com o trabalho se faz através da identidade de trabalhador que se mantém como referência identitária, pois não se rompem os modelos de identificação preservados pela memória. É nessa lógica em que o contexto sócio-cultural a partir da positividade conferida ao trabalho, em que não se rompem os laços subjetivos com a vida laboral mesmo com a aposentadoria e a velhice, que ganha sentido o trecho introdutório:

"A memória do trabalho é o sentido, é a justificativa de toda uma biografia. Quando o Sr. Amadeo fecha a história de sua vida, qual o conselho que dá? De tolerância para os velhos, tolerância mesmo com aqueles que se transviaram na juventude. Eles também trabalharam." (Bosi, 1987, p. 399)

É o sentido ético conferido ao trabalho na sociedade contemporânea que articula a interpretação e o inter-relacionamento entre trabalho, aposentadoria e terceira idade, em que a dimensão subjetiva ganha significado e justifica ou a permanência no mundo formal do trabalho ou o vínculo simbólico através da identidade de trabalhador. 


\section{Referências bibliográficas}

1 ARENDT, Hanna. A Condição Humana. Rio de Janeiro, Forense-EPU, 1981.

2 BERND, Zilá. Da Arte de Viver mais Frouxo. Zero Hora, Porto Alegre, 9de dezembro de 1996 p. 21.

3 BOSI, Ecléa. Memória e Sociedade: lembranças de velhos. São Paulo, Queiroz-EDUSP, 1987.

4 COSTA, Jurandir Freire. Psicanálise e Contex to Cultural. Rio de Janeiro, Campus, 1989.

5 DECCA, Edgar de. O Nascimento das Fábricas. 6 Ed., São Paulo, Brasiliense, 1988

6 HABERMAS, Jirgen. Para a Reconstrução do Materialismo Histórico. 2 Ed., São Paulo, Brasiliense, 1990

7 HELLER, Agnes. O Cotidiano e a História. 3 Ed., São Paulo, Paz e Terra, 1989.

8 ERUSALINSKY, Alfredo. Quanto Vale um Homem? Jornal da Universidade. Porto Alegre, UFRGS, p. 2 out. 1998

9 KRASSOIEVITCH, Miguel. Psicoterapia Geriátrica. México, Fondo de Cultura Económica, 1993

10 MARGLIN, Stephen. Origem e Funções do Parcelamento das Tarefas. IN: GORZ, André (Org.) Crítica da Divisão do Trabalho. São Paulo, Martins Fontes, 1989, p. 37-78

11 SALGADO, Marcelo Antônio. Aposentadoria e Ética Social. Revista da 3aIdade, São Paulo, v. 2, n. 2 p. 48 1989.

12 SANTOS, Maria de Fátima. Identidade e Aposentadoria. São Paulo, EPU, 1990.

13 THOMPSON, E. P. OTempo, a Disciplina do Trabalho e o Capitalismo Industrial. IN: SILVA, Tomaz Tadeu da (Org.). Trabalho, Educação e Prática Social. Porto Alegre, Artes Médicas, 1991, cap. 2

14 SÉVE, Lucien. Personalidade em Gestação. IN: SUVEMA, Paulo \& DORAY, Bernard (Org.) Elementos para uma Teoria Marxista da Subjetividade. São Paulo, Vértice, 1989, cap. 5. 